\title{
Putting the Biophysical (Back) in Economics: A Taxonomic Review of Modeling the Earth-Bound Economy
}

\author{
John Sherwood ${ }^{1}\left[\right.$ D $\cdot$ Michael Carbajales-Dale ${ }^{1} \cdot$ Becky Roselius Haney ${ }^{2}$
}

Received: 4 June 2019 / Revised: 21 February 2020 / Accepted: 25 February 2020 / Published online: 13 March 2020

(c) The Author(s) 2020

\begin{abstract}
Economists rarely model the economy as explicitly bound by earth's ecological systems. Modeling the dynamic interactions of both human and non-human systems is admittedly a challenging task, as it requires expertise from multiple disciplines. Within the last 10 years, a wide variety of research papers have been published that include some biophysical aspects in a model of the economy. These papers all have one thing in common: the model of the economy includes physical and/or energetic exchanges, as well as monetary exchange. This theme is what defines the emerging sub-discipline of biophysical economics, BPE. BPE models of the economy originate from a variety of disciplines, and thus BPE research articles are published across a wide spectrum of academic journals. As inter-disciplinary researchers ourselves, we want to understand what BPE modeling approaches have been used so far. In this paper, we examine and classify over one hundred published articles that use biophysical models of the economy. Although BPE modeling approaches are quite varied, grouping the research by common characteristics reveals several active research areas. We highlight recent papers that are helpful examples of the most popular BPE modeling strategies. Gaps also exist. Several modeling approaches have not been used in published works yet. We identify which of those gaps could be promising avenues for future research. We conclude by suggesting which BPE modeling approach might be particularly appropriate for a variety of research questions.
\end{abstract}

Keywords Review $\cdot$ Modeling $\cdot$ Production function $\cdot$ Systems dynamics $\cdot$ Input-output $\cdot$ Agent-based model

\section{Introduction}

Biophysical constraints are largely ignored in conventional economic models. Of course these conventional models do not explicitly deny the biophysical reality that the economy depends on the availability of natural resources, or even that the economy takes advantage of ecosystem services such as water purification, carbon sequestration, and erosion control. However, these realities are generally not considered limiting enough to be of concern.

Electronic supplementary material The online version of this article (https://doi.org/10.1007/s41247-020-00069-0) contains supplementary material, which is available to authorized users.

John Sherwood

jgsherw@clemson.edu

1 Department of Environmental Engineering and Earth Sciences, Clemson University, Clemson, SC, USA

2 Department of Economics, Calvin University, Grand Rapids, MI, USA
To be fair, instances of natural resource depletion leading to major economic contraction are rare in the modern era and early attempts by economists to model or account for biophysical limits on the economy were unsuccessful. In 1798, economist Thomas Malthus modeled the economy as bound by the quantity of agricultural land. And, because the quantity of land available to feed the population could only grow linearly, but the population would grow exponentially, he predicted catastrophic outcomes (Malthus 1878). What Malthus' model missed was the impact of technology. Human ingenuity improved the quality of land, rendering the physical quantity of land a seemingly non-binding constraint. Indeed, the subsequent increase in the quantity and quality of food production ushered in one of the greatest eras of improvement in human health and well-being.

In 1866, renowned mathematical economist William Stanley Jevons' predicted that the rebound effect from England's improvements in energy technology would outstrip the available reserves of coal. He called for policy to restrain economic growth and keep the economy from an unsustainable path. (Jevons 1866). However, his policy suggestions 
went unheeded and his predictions were proved wrong. Again, the economy skirted looming constraints through technological innovation. Thus, this more sophisticated biophysical model of the economy proved lacking as well.

These failures may have inadvertently led economists to believe that technological innovation will always allow the economy to ignore biophysical limits. And, to be fair, that is a possibility, though an unlikely one. As the Industrial Age enters its fourth century, there is reason to believe that past technological advances did not abolish biophysical constraints, but instead merely postponed them. For example, while diminishing reserves of underground coal in the UK and Eastern US were replaced with coal mined from near surface resources (e.g., in Wyoming's Powder River Basin), the less obvious depletion of $\mathrm{CO}_{2}$ sequestration capacity (through deforestation) continued. Similarly, as diminishing conventional oil reserves are being supplemented with 'unconventional oil' from oil sands or tight oil resources, the increasing energy costs may become unsustainable. These and other substitutions skirt obvious natural resource limits in the short-run, but are subject to seemingly less obvious ecological limits in the long-run. Thus, the urgency to understand the relationship between economics, resources, and ecological systems might be more apparent to those outside the economics discipline.

As Malthus and Jevons demonstrated, developing a useful biophysical model of the economy is challenging. Biophysical models of the economy require knowledge from a variety of additional disciplines, including earth and environmental science, biology, and ecology, as well as industrial and mechanical engineering, to name a few. Development of biophysical models of the economy is necessarily multi-disciplinary. Unsurprisingly, most of the biophysical models of the economy have been developed outside of the economics discipline because ecosystem services are not traded in the market, nor are ecological systems necessarily well-understood by economists.

The field of biophysical economics provides a named space for the diverse body of research that is linked by a common goal: to elucidate the physical reality of the earthbased economy. BPE models must capture complex interactions between human and natural systems. Many focus particularly on modeling thermodynamics and energy as part of the economic systems of extraction, production, distribution, consumption, and disposal. The advantage of BPE models is that researchers from a wide variety of backgrounds can work together to understand these systems. The disadvantage is that emerging, multi-discipline research fields such as BPE can be a daunting landscape to navigate. It is not easy to understand the full range of BPE research that already exists, let alone identify potential openings for new BPE research questions. Given the urgency of the questions that biophysical economics research can address, coupled with the widely diverse set of approaches used by practitioners, a way to understand the current biophysical economics modeling landscape is a necessity.

The contribution of this paper is to develop a taxonomy for biophysical models of the economy and classify a sample of over $100 \mathrm{BPE}$ articles published in the last 10 years. This taxonomy classifies articles based on six characteristics:

1. Framework: does action in the model flow from the topdown or bottom-up?

2. Spatial scale: is the model more local or global in scale?

3. Time horizon: is the time frame short or long term?

4. Modeling ethos: is the model more empirical or theoretical?

5. Origins: does the model emerge primarily from natural or from social sciences?

6. Mechanism: does the model rely on statistical inference or simulated outcomes?

Each characteristic is described in detail in the "Taxonomy" section.

Classifying BPE research through this taxonomy helps to identify approaches that have attracted high levels of research activity. The taxonomy also reveals under-utilized approaches that could be successful new avenues of future research. Gaps within the modeling taxonomy may indicate open niches, or room for new biophysical economic models. Preliminary analysis of the gaps in the taxonomy suggests that promising openings for future research include for example, how the geographic distribution of people and resources affect biophysical constraints. Or, what policy interventions might be necessary to transition smoothly to a renewable energy based economy.

This paper proceeds as follows. We first provide a brief history of biophysical economics as it emerged from within economics and from other disciplines. We identify additional reviews of BPE literature, as well. We then describe the wide variety of modeling approaches that have appeared so far in the field of biophysical economics. We describe each of the six characteristics that are used to categorize them and show how four examples of recent research are classified using the taxonomy. Classifying 110 BPE articles according to the taxonomy allows researchers interested in biophysical economics an opportunity to see the broad landscape of modeling approaches that have been published so far. The paper concludes with suggestions of areas that are ripe for additional research. 


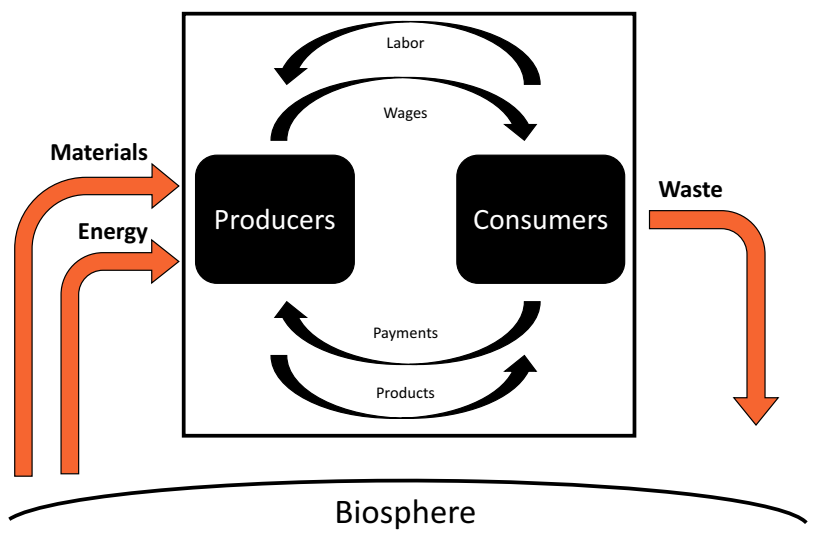

Fig. 1 BPE's circular flow model Adapted from Heun et al. (2015), Hall et al. (1986). The orange arrows represent biophysical pathways that are not captured in conventional economic models

\section{What Makes a Model of the Economy a Biophysical Model?}

Mainstream environmental economic models examine the markets and market failures related to natural resources, energy, and waste. These models perceive natural resources, energy, and waste through the lens of financial flows. In contrast, biophysical models of the economy also account for the physical flows of natural resources, energy, and waste through the economy. In most cases, resources, energy, and waste are viewed as central players in BPE models of the economy. Palmer's (2018) Energies article provides an especially clear definition of biophysical economics.

Biophysical economics is the study of the ways and means by which human societies procure and use energy and other biological and physical resources to produce, distribute, consume and exchange goods and services, while generating various types of waste and environmental impacts. Biophysical economics builds on both social sciences and natural sciences to overcome some of the most fundamental limitations and blind spots of conventional economics. It makes it possible to understand some key requirements and framework conditions for economic growth, as well as related constraints and boundaries.

Conventional economics models the economy as a separate and distinct entity. The economy is modeled as a circular flow of goods and services in one direction, and monetary flows in the other. In conventional economics textbooks, the circular flow economy is presented as disembodied and disconnected from the earth upon which it is based.
The contrast between BPE and conventional economics is made clear in the BPE version of the circular flow model as depicted in Fig. 1.

The conventional economic circular flow model is still included, but is embedded and enmeshed within the biosphere. The diagram not only recognizes the necessity of material and energy as inputs to a functioning economy, but also recognizes the inevitability of outputs-presently waste deposited back to the biosphere. The non-monetary flows of materials, energy, and waste that are intrinsic to the economy are made visible alongside the monetary flows and flows of economic goods and services. This coupling between economy and biosphere is critical to holistically understand constraints to economic opportunities and the impacts of economic activity upon the natural environment.

\section{The Biophysical Economics Renaissance}

As mentioned above, biophysical economics is not new. In fact, the name "economist" was coined by the the Physiocrats, arguably the first biophysical economists in the modern era (Miller and Blair 2009). The Physiocrats were led by French physician Francois Quesnay and advocated the position that agriculture was the source of a country's wealth. This rivaled earlier ideas of mercantilism (led by Sir William Petty, the first econometrician) that described a country's wealth as coming from the accumulation of silver and gold.

Francois Quesnay is likely most known for his Tableau Economique, an economic model depicting the flow of goods through economic sectors. Most notably, Quesnay saw no "value-added" in manufacturing or service industries-agriculture and land output was the sole source of wealth (Quesnay et al. 1972). Despite this flaw, the Tableau Economique went on to influence the foundations of national accounts and input-output economics and Quesnay is known as one of the first economists who valued an economy's reliance on natural resources.

Outside the field of economics, the scientific work of Sadi Carnot, Rudolf Clausius, and Lord Kelvin formalized the laws of thermodynamics. These laws describe the nature of energy, but the second law is of particular importance to economics. The second law of thermodynamics roughly states that isolated systems tend toward an equilibrium, at which point no useful work can be done. For a system to maintain a non-equilibrium state and continue to do work, it requires a continual flow of low entropy (high quality) energy. That is, the system must be open (i.e., have inputs) to perform tasks and/or grow. The economy is such a system. One goal of biophysical economics is to stay true to these thermodynamic principles.

Scientists outside the field of economics began to see the implications of these laws on the economy-because 
economies exist in a physical reality, they must have fundamental physical limits or constraints. Cleveland $(1987,1999)$ go into more detail concerning this early theory development phase. Some notable researchers include Lotka, who linked energy quality to biological life (Lotka 1922), Cottrell, who studied "surplus energy" (a precursor to Energy Return on Investment, EROI) and its role in societal development (Cottrell 1955), M. K. Hubbert, who developed the theory of peak oil (Hubbert 1949), and Odum, who posited an energy theory of value and developed systems ecology (Odum 1994). Cleveland et al. studied the relationship between energy use and GNP (Cleveland et al. 1984).

Within the economics discipline, Nicholas GeorgescuRoegen and Herman Daly pioneered the modern biophysical approach to economic theory. In 1971, Georgescu-Roegen's The Entropy Law and the Economic Process introduced the implications of entropy for an economy (Georgescu-Roegen 1971). An economy relies upon low entropy (high quality) resources to fuel the production of goods. Furthermore, economies emit high-entropy (low quality) wastes (e.g., waste-heat). Georgescu-Roegen is one of the first economists in the modern era to acknowledge the biophysical constraints of the global economy (Kåberger and Månsson 2001; Ayres 1999). And, although somewhat controversial, GeorgescuRoegen even went so far as to suggest that the second law might apply to physical matter as well as energy-economies consume highly concentrated ores (e.g., copper or lithium) and then dispose of materials in a low concentration waste-stream (e.g., landfills).

Herman Daly built on Georgescu-Roegan's biophysical approach as he developed the concept of steady-state economics. In contrast to mainstream economic theory that requires ever-increasing levels of economic output to maintain growth in standards of living, Daly posits that a steadystate economy, in combination with significant recycling programs, can maintain growth in standards of living, while also acknowledging and incorporating the biophysical limitations of the economy (Daly 1991). The implications and pathways towards a steady-state is a growing research thrust that has recently gained popularity (Ghisellini et al. 2016).

Arguably the first holistic biophysical model of the economy in the current era is the seminal, Limits to Growth work led by Donella Meadows (Meadows et al. 1972). Advances in computer technology opened the door for their highly sophisticated model and simulated outcomes of the interaction between economic and biophysical systems. Their model explored the impacts of population growth, resource depletion, and pollution externalities on societal growth. Harking back to Malthus and Jevons, their simulations resulted in a growth patterns that exhibited overshoot and collapse. Only scenarios of concerted and sustained efforts to mitigate damaging effects of over consumption were able to avoid unplanned collapse. The study findings generated much controversy within the academic and popular literature; however as the decades have unfolded since their work, the predicted patterns of the model have not been proven inconsistent with reality. Malthus and Jevons' theories may be proven correct after all (discounting their timeline), although that would not be a win to celebrate.

Since Daly and his contemporaries' work, many BPE researchers have turned to solidifying, building out, and finetuning the theoretical framework that was largely outlined in the 20th century. Hall and Klitgaard (2018), for example, wrote Energy and the Wealth of Nations, an introductory textbook to biophysical economics. Now, more research activity is trending towards quantitative modeling rather than qualitative theorizing. A few researchers have been at the forefront of this modeling effort. Many researchers have worked on analytical and statistical models. Ayres and Warr (2010); Heun et al. (2017) have worked on including energy in aggregate production functions. Murphy and Hall (2010); Brandt et al. (2011); Dale et al. (2011) and others have worked on modeling EROI for various fuels and society. King (2016); Brand-Correa et al. (2017); Heun et al. (2018) and others have explored using input-output tables to better understand the role of energy in economies. Other researchers have focused on simulations of longer-term trends. Dale et al. (2012b); Sverdrup et al. (2017a); Motesharrei et al. (2014) and others have developed systems dynamics models of society to study long term energy transitions and resource scarcity. Voudouris et al. (2011); Sherwood et al. (2017) and others have been developing Agent-Based models to study biophysical economics. These various modeling approaches are usually modifications or adaptations of the models used in similar disciplines. For more about the history of biophysical economics, see for example Dale et al. (2012a); Cleveland (1987, 1999); Røpke (2004).

\section{Biophysical, Environmental, and Ecological Economics}

The economics discipline does model aspects of the natural environment. Biophysical economics articles published in economics journals usually categorize their subject matter under the subject code for "Agricultural and Natural Resource Economics; Environmental and Ecological Economics."

Environmental and ecological economics articles make up about $7 \%$ of all economics articles. This proportion remained constant throughout the years spanning 1969 to 2007 (Kelly and Bruestle 2011). What did change during that time period was a proliferation of specialized journals 


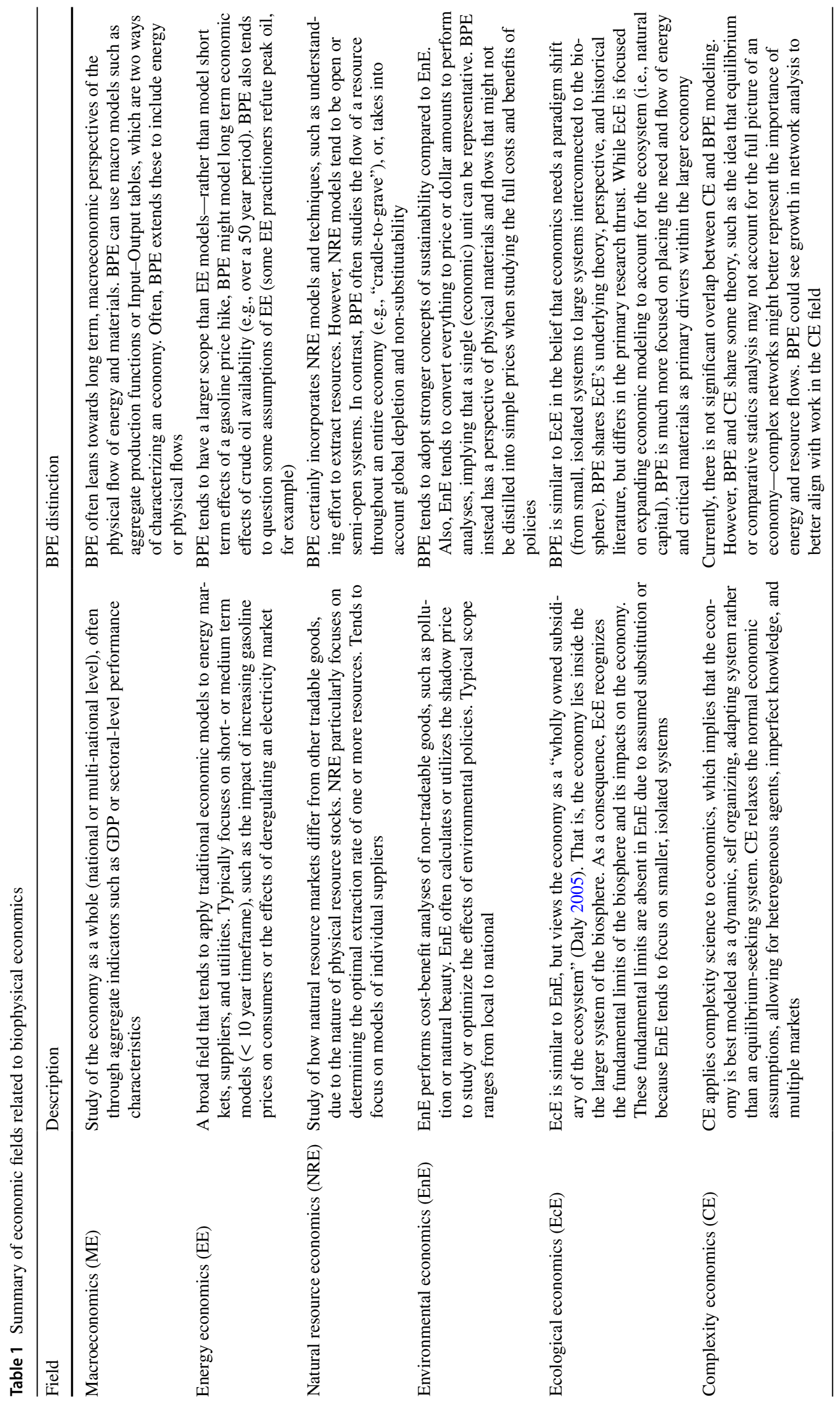




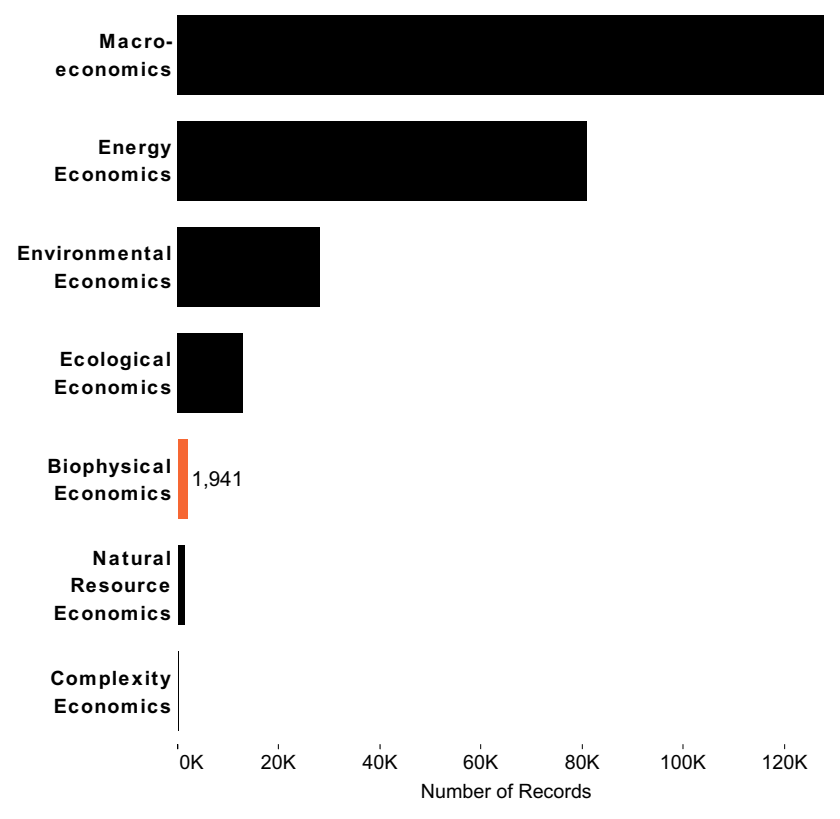

Fig. 2 Relative size of relevant economic fields based on peerreviewed literature search on EBSCO's Academic Search Complete using all databases. Search terms included [subject] Econ* within Title OR Subject terms OR Abstract

in economics. Of the 842 journals in economics, 605 are specialty journals. The diffusion of research journals is particularly common for BPE subjects. More than $80 \%$ of environmental and ecological economics articles are published in specialty journals, a higher percentage than any other subject in economics (Kelly and Bruestle 2011, Table 6). ${ }^{1}$

BPE models also appear in macroeconomics, energy economics, natural resource economics, and complexity economics. Table 1 provides a concise description of each of these subfields of economics and discusses the particular ways within them that BPE models are used.

Surprisingly, biophysical economics has appeared in a similar number of publications over the last decade as the traditional field of natural resource economics. Figure 2 shows the number of BPE research articles published as compared to the number published in each of the economic fields listed in Table 1. These numbers were tabulated based on literature searches using each field as a search term. ${ }^{2}$

\footnotetext{
${ }^{1}$ Specialty journals are defined as journals where over $50 \%$ of their articles use the same major subject code (Kelly and Bruestle 2011).

${ }^{2}$ In Fig. 2, bioeconomic research articles were included as BPE. However, bioeconomics tends to study the micro-economics of fisheries and forestry and could instead be grouped with natural resource economics (Clark 2010). In either case, biophysical economics is emerging as a growing field.
}

\section{Additional Surveys of Biophysical Economics}

The literature analyzed in this paper is only comprised of BPE modeling efforts published within the last 10 years. This paper does not discuss the details of each model, or weave together an understanding of a specific group of models. The strength of this paper lies in its comprehensive categorization of various BPE models to understand the modeling landscape. BPE modeling approaches appear in a variety of other disciplines' publications as well, including industrial ecology, geology, engineering disciplines, and environmental science. Other recent and more traditional BPE and BPE-related reviews go into more detail for their respective subject areas, and are summarized in Table 2 for the interested reader.

\section{The Biophysical Economic Modeling Landscape}

In addition to overlapping and interacting with several disciplines, biophysical economic studies use similar, though often modified, modeling strategies. These include aggregate production functions, input-output tables, systems dynamics, life cycle assessment, and many others. The choice of model depends partially on the modeling goal, but also on data availability and domain knowledge (North and Macal 2007; Hamill and Gilbert 2015; Sterman et al. 1991). An interesting example is provided by the World 3 model, developed during the seminal Limits to Growth study (Meadows et al. 1972). The goal of the model was "to identify "different possible futures" by "sketching alternative scenarios for humanity as we move toward 2100." (Meadows and Randers 2012, p. xvii). This meant that model results were not meant to be treated as predictions, but instead "merely indicate the general direction our system, as it is currently structured, is taking us." (Meadows et al. 1972, p. 43). This, however, did not stop many critics from rebuffing the model by pointing out that "predictions" did not come to pass in any particular year (Bardi 2011). That is, some readers of the model results assumed a different modeling goal than the designers intended.

We postulate that biophysical economic models can be categorized in many ways (described in the "Taxonomy" section). The categorization of models may elucidate several things about the field: 1 . What topic areas have been addressed? 2. What modeling types have researchers focused on? 3. What modeling goals are prominent? And, categorization may help point out potential gaps in the current modeling landscape. Is the current landscape of BPE models missing any important areas of research that can be identified through a taxonomic analysis? 
Table 2 Summary of recent literature reviews related to biophysical economics

\begin{tabular}{|c|c|c|}
\hline References & Title & Description \\
\hline Dale et al. (2012a) & $\begin{array}{l}\text { Global energy modeling-a biophysical approach } \\
\text { (GEMBA) part 1: an overview of biophysical econom- } \\
\text { ics }\end{array}$ & $\begin{array}{l}\text { Provides a historical review of BPE and outlines some } \\
\text { prominent BPE models }\end{array}$ \\
\hline Hardt et al. (2017) & $\begin{array}{l}\text { Ecological macroeconomic models: assessing current } \\
\text { developments }\end{array}$ & $\begin{array}{l}\text { Reviews } 22 \text { ecological macroeconomic models and their } \\
\text { ability to handle post-growth scenarios }\end{array}$ \\
\hline Palmer (2018) & $\begin{array}{l}\text { A biophysical perspective of IPCC integrated energy } \\
\text { modeling }\end{array}$ & $\begin{array}{l}\text { Critiques current integrated assessment models from a } \\
\text { biophysical perspective }\end{array}$ \\
\hline Rye and Jackson (2018) & A review of EROEI-dynamics energy transition models & $\begin{array}{l}\text { Historical review of EROEI-related models. Focuses on } \\
\text { systems dynamics rather than I-O approaches }\end{array}$ \\
\hline Earles and Halog (2011) & Consequential life cycle assessment: a review & $\begin{array}{l}\text { Reviews cLCA literature with focus on opportunities to } \\
\text { better bridge LCA studies with economic models at a } \\
\text { macro scale }\end{array}$ \\
\hline Li et al. (2015) & $\begin{array}{l}\text { A review of socio-technical energy transition (STET) } \\
\text { models }\end{array}$ & $\begin{array}{l}\text { Reviews a number of IAM or similar models that focus on } \\
\text { energy transitions }\end{array}$ \\
\hline Hansen et al. (2019) & $\begin{array}{l}\text { Agent-based modeling and socio-technical energy transi- } \\
\text { tions: a systematic literature review }\end{array}$ & ABM specific review of energy transition modeling \\
\hline $\begin{array}{l}\text { Melgar-Melgar and Hall } \\
\text { (2019) }\end{array}$ & $\begin{array}{l}\text { Why ecological economics needs to return to its roots: } \\
\text { the biophysical foundation of socio-economic systems }\end{array}$ & $\begin{array}{l}\text { Provides historical summary of Ecological Economics and } \\
\text { BPE, and describes various BPE methodologies }\end{array}$ \\
\hline
\end{tabular}

For this paper, we have selected 110 articles containing biophysical economic models to analyze based on their topics addressed and model characteristics.

\section{Article Selection Criteria}

In order to capture as representative a sample of recent models as possible without generating too large of a potential set, we developed a set of search and screening criteria in our literature search. For our initial search, we included the journals: Biophysical Economics and Sustainability (formerly Biophysical Economics and Resource Quality), Ecological Economics, Ecological Modelling, Energy Economics, Energy Policy, and Resource and Energy Economics. We acknowledge that BPE researchers publish elsewhere as well, but we believe these journals provide a representative cross-section of the field (the journals Energy, Applied Energy, and Energy Policy all receive similar BPE models, for example). We also added 20 known BPE models published elsewhere. These models were categorized when developing the categorization criteria, but were outside the final defined scope of the literature search. We additionally added 7 papers recommended by reviewers. Our search process followed the following steps:

1. Using ScienceDirect, filter to only include research articles from 2009 to 2019 (results are provided in the supporting materials).

2. For each journal, search with keywords:

- Model, input-output
- Model, systems dynamics

- Model, production function

- Agent-based model

\section{Perform first screening of 1366 results}

We limited the initial search with certain modeling framework keywords to attempt to avoid articles discussing conceptual or qualitative models or reviews. We acknowledge that, by focusing specifically on these keywords, we may miss other BPE models that do not fall into one of these categories, such as a generic analytical model defined by a few equations (though, the search did pick up some of these models, usually under the "production function" search query). The initial search provided a total of 1366 papers to screen.

Our initial screening process consisted of reading the title of the paper to determine if it did not fit a broad definition of "BPE model." Our primary guide here is the definition of biophysical economics referenced in the "What Makes a Model of the Economy a Biophysical Model?" section. To align with the definition of BPE, we kept articles that hinted at including both an economic component, and physical resources or environmental flows within industrialized society. A BPE model either explicitly accounts for physical limits in non-monetary units of physical substances in or around an economy (in addition to some economic component), or a BPE model frames the interpretation of a monetary-based model through a BPE perspective (such as a model critiquing the cost-share of energy and its impacts on GDP). For this first screening process, our aim was to be inclusive rather than exclusive. 
That is, we only excluded papers that clearly were not a BPE model. An article was discarded if:

1. The article only mentioned emissions, $\mathrm{CO} 2$, or carbon footprinting in the context of climate change, such as "Structural decomposition analysis and input-output subsystems: Changes in $\mathrm{CO} 2$ emissions of Spanish service sectors (2000-2005)" (Butnar and Llop 2011).

- Excluded because short term environmental concerns, without much discussion of physical limits or the root causes of climate change, align closer to environmental economics than biophysical economics.

2. The article was focused on land use or agriculture, such as "The role of farmers' property rights in soil ecosystem services conservation" (Foudi 2012).

- Excluded because, while a macroscopic land use or agriculture study could fit within BPE, a microeconomic or small-scale/local perspective rarely fits within the BPE definition of "...the ways and means by which human societies procure and use energy and other biological and physical resources." Here, the title does not imply investigating fundamental limits or constraints on soil at a societal level.

3. The article only referenced pricing externalities, such as "Pricing emission permits in the absence of abatement" (Hintermann 2012).

- Excluded because pricing externalities and emissions abatement fall within the realm of energy economics, and do not necessarily examine physical limits or the root cause of emissions (economic output and resource usage).

4. The article focused on non-humans (often within the journal Ecological Modelling), such as "Evaluating impacts of intensive shellfish aquaculture on a semiclosed marine ecosystem" (Han et al. 2017).

- Excluded because the definition of BPE limits the field to human societies.

5. The article had no clear link to economics, such as "Foodweb modeling for polychlorinated biphenyls (PCBs) in the Twelvemile Creek Arm of Lake Hartwell, South Carolina, USA" (Rashleigh et al. 2009).

- Excluded because, while PCBs are a pollutant generated by humans, BPE models must include an economic component.

Screening article titles reduced the pool to 207 potential BPE models. These 207 articles were then screened based on the abstract and conclusion. This second stage followed

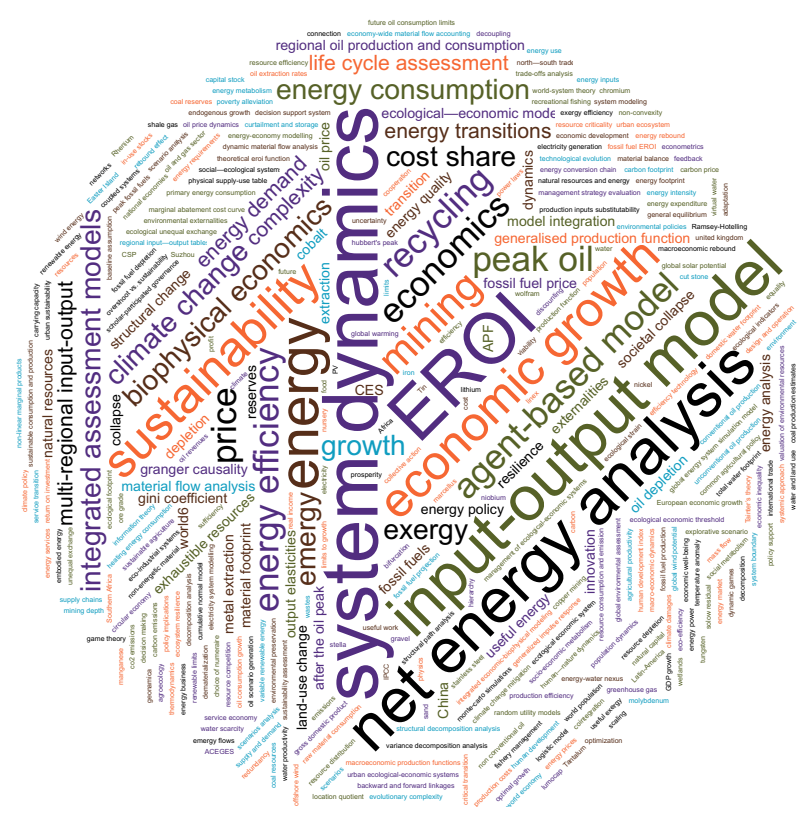

Fig. 3 Word-cloud of keywords for all 110 papers. Larger words indicate more occurrences across the articles

all of the discard criteria above, but additionally looked for commentary on the physical nature of resources or potential ecological constraints on the economy. Lack of BPE specific commentary often meant the article better aligned with one of the neighboring economic disciplines described in Table 1. Additionally, the paper needed to include a quantitative model. Abram and Dyke (2018), for example, did not pass the second screening. Though the title "Structural Loop Analysis of Complex Ecological Systems" and abstract hint at BPE commentary and a quantitative model, the paper itself details a specific tool used to analyze system dynamics models and does not focus on a specific BPE model. This second screening reduced the pool to 110 articles that were categorized according to the criteria outlined in the "Taxonomy" section. A full list of all models considered is found in the supporting materials.

\section{Topic and Keyword Analysis}

To better understand the diversity of selected models, we collected and analyzed all of the articles' keywords. Figure 3 displays a word-cloud of the keywords. Keywords that occur more frequently throughout the dataset have a larger font. From this word-cloud, we can determine that many papers used keywords such as "system dynamics" and "EROI," while other keywords such as "resource criticality" occur infrequently. Note that we adjusted certain keywords to better align within this analysis, such as combining "EROI," "EROEI," and "energy return on investment." 


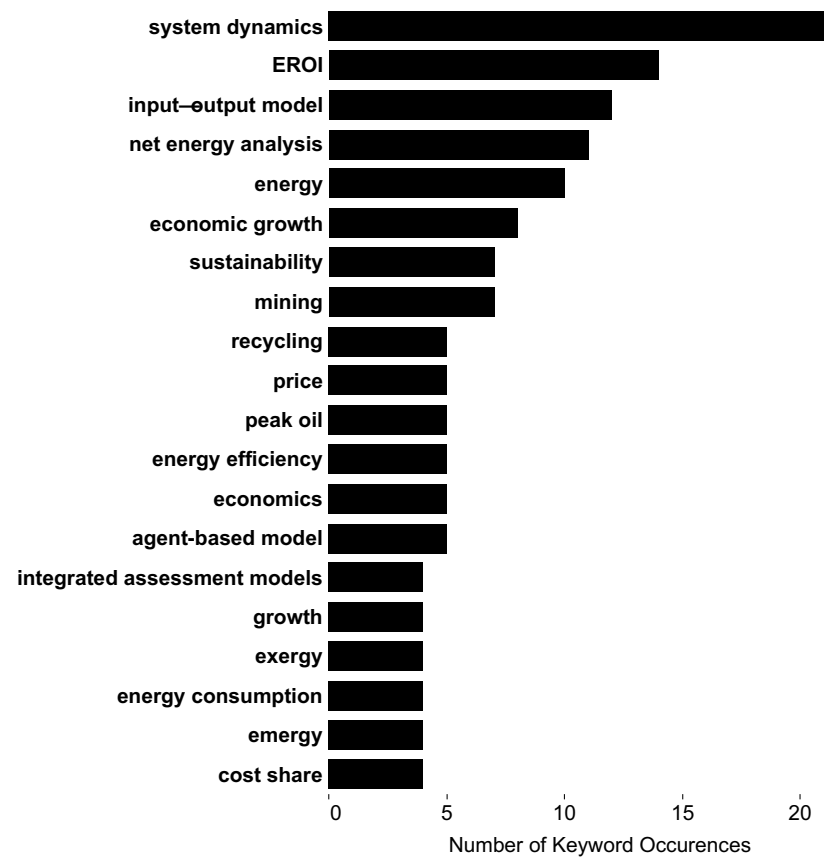

Fig. 4 Number of occurrences of the top 20 keywords from all 110 articles

Additionally, Fig. 4 shows the number of occurrences for the top 20 keywords. By viewing Figs. 3 and 4, we can see that both methodology-based keywords (such as "net energy analysis" or "input-output model") and applicationbased keywords (such as "EROI" or "mining") are popular. Researchers writing papers within biophysical economics may want to include at least one of these popular keywords in their manuscript for more visibility, if possible.

Based on trends within the keyword analysis, we then mapped the articles to seven topic areas to further understand common trends in biophysical economics modeling. These topic areas were selected by identifying common, but discrete themes among the papers. The topic areas include: 1. "Energy Economy"-macroeconomic models such as an economy-wide EROI or rebound-effect study; 2. "Energy Resources and Technology"-models focused on a specific sector or technology such as peak oil or solar PV; 3. "Materials"-models studying the depletion of non-energetic, nonrenewable substances, particularly industrial feed-stocks, such as lithium or iron; 4. "Resources"- models studying renewable resources, or resources in the context of ecology rather than industry. These include agriculture, water, or land use; 5. "Interconnections"-models of a holistic nature that capture multiple categories, such as the Human and Nature Dynamics (HANDY) model (Motesharrei et al. 2014); 6. "Climate"-models focused on the relationship between biophysical economics and climate change; and 7. "Policy"-_models focused on policy and stakeholder action,

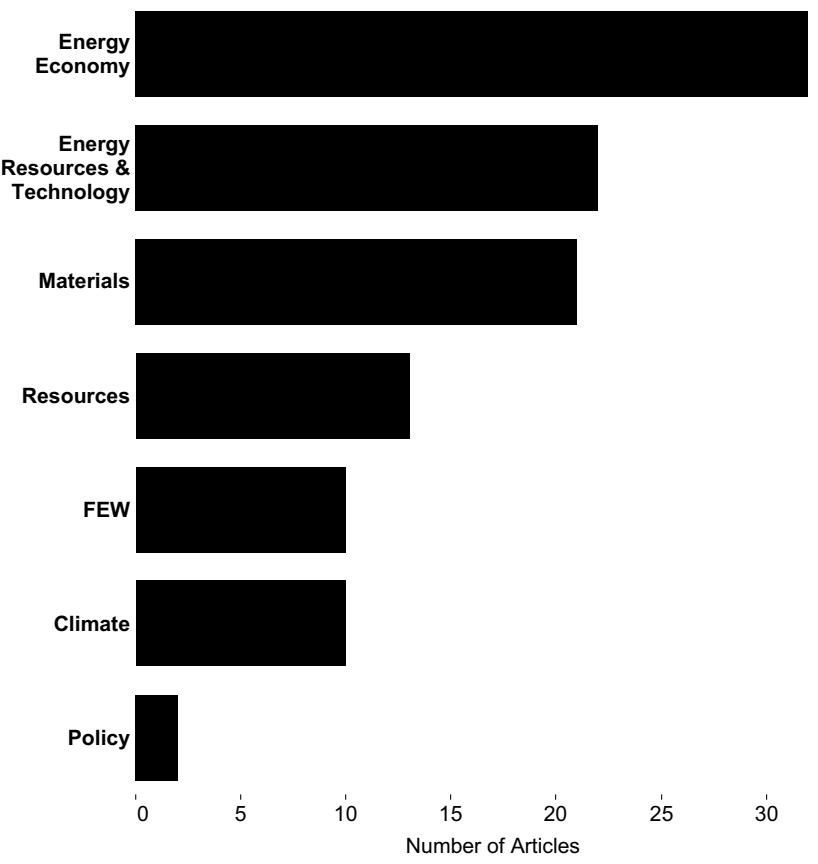

Fig. 5 Topic grouping of all 110 BPE models

such as a dynamic ecological footprint model to examine the impact of different policy scenarios (Jin et al. 2009).

Figure 5 displays the number of papers within each of these broad categories. The figure shows that the majority of models investigate energy-related subjects. Indeed, much of biophysical economics has been focused on questions related to energy return on investment and the role of energy in the economy. However, there are also a significant number of models that focus on non-energetic materials and resources. These models hit the "materials" economy-biosphere link present on Fig. 1, the biophysical circular flow diagram. Figure 5 also seems to indicate that there are relatively few models focused on interconnections, climate, and policy. These categories seem ripe for future growth.

In addition to this topical analysis, we create a taxonomy, or model classification scheme, to categorize models according to characteristics of the models themselves, outside of the topics they address.

\section{Taxonomy}

In general, different models can be qualitatively mapped according to different characteristics. These characteristics are: Framework, Spatial scale, Time horizon, Ethos, Origins, and Mechanism. For each characteristic, we use an ordinal 1-5 scale to designate the potential categories of that characteristic. Note that though we use a 1-5 scale, we make no value or effectiveness judgments. Neither 1 nor 5 is "the 
Table 3 Framework taxonomy criteria

\begin{tabular}{llllll}
\hline Characteristic & 1 & 2 & 3 & 4 & 5 \\
\hline Framework & Individual-based model & Agent-based model & Input-output model & Systems dynamics & Aggregate production function \\
\hline
\end{tabular}

best"- the quality of a specific model is wholly dependent on how well it aligns with its intended application. Additionally, the categories may not be evenly spaced-they are merely a logical ordering. That is, a category of 3 is not necessarily directly halfway between two and four, but the order 2-3-4 is logical.

\section{Framework}

The framework characteristic is the big-picture structure of a model type. The categories are Individual-based Model, Agent-based Model, Input-Output Model, Systems Dynamics, and Aggregate Production Function. The framework characteristic describes something broader than "model structure." Two systems dynamics models may have vastly different structures. But, as systems dynamics models, they will have the same overall rules, mathematical concepts, and types of algorithms governing them.

In the taxonomy, a category of 5 represents models similar to aggregate production functions-simple, highly aggregated analytical models that collapse highly distinct and variable real-world phenomena into a minimal number of variables.

Systems dynamics models or similar are given a category of 4, as they can capture more details of the dynamics of a system. As system dynamics models are one of the most prevalent approaches we find, here we provide further description of this approach. A systems dynamics model identifies stocks and flows within a system and determines feedback loops in order to build system-level equations that relate various parameters. An example systems dynamics model might be of the world economy, such as the World3 model in Limits to Growth (Meadows et al. 2004). Often (though not a requirement), the equations describe aggregated flows at the economy or sector level, such as lumping all production, emissions, or energy use into a single parameter. These parameters might miss important details of what they represent, like limitations of specific energy technologies. Furthermore, the design and structure of a systems dynamics model is static throughout its runtime. Stocks and flows representing portions of the economy do not spontaneously switch trading partners.

Input-output modeling or similar are given a category of 3 , because they can be highly disaggregated with numerous distinct industries or processes (assuming data availability).
A category of 2 represents agent-based models. Agent-based models (ABM) are relatively new modeling approaches and we provide further description of them here. ABM often model micro-economic behavior at the level of the individual or firm. Macroeconomic outcomes (desired indicators) emerge from agents' interactions. While also incorporating feedback loops, an agent-based model is adaptive in ways that system dynamics cannot be, in part because the major driver within the model is an individual rather than system. Social networks and relationships can form or dissolve because of agents' changing behavior. Intra-system, emergent, macro-level dynamics, such as income inequality and technological adoption, are more able to represent realistic variability because they need not be constrained by a static set of functions. For example, Rai and Robinson (2015) developed an agent-based model of household solar panel adoption within Austin, Texas. The model simulated both economic and social influences (such as geographic neighbors installing PV systems) on the decision to invest in solar panels, and accurately simulated city-wide solar adoption trends (the emergent behavior being studied).

Lastly, a category of 1 for the framework characteristic represents true individual-based models, where an agent is a specific person or entity, rather than an industry or country (a country might often be the "agent" in ABMs, such as Voudouris et al. (2011)) The Rai and Robinson (2015) example would be categorized as an individual-based model, as the "agent" is a specific household, the lowest level of analysis for household solar adoption.

In summary, this characteristic captures a modeling framework's flexibility and ability to model varying levels of real-world phenomena (Table 3 ). ${ }^{3}$

\section{Spatial Scale}

This dimension characterizes the overall scope or intended application of a model. A systems dynamics model may represent the global economy, a specific country's economy, or one city's economy using the same equations. However, each scale still encounters the limitations of the modeling

\footnotetext{
${ }^{3}$ Here, ability does not relate to a specific model's success or failure at modeling its intended application. We use ability here to mean that some models are better suited to model, for example, very detailed complex systems than others. The structure or framework of aggregate production functions is unable to capture many phenomena that an IO or agent-based model may seek to investigate.
} 
Table 4 Spatial scale taxonomy criteria

\begin{tabular}{llllll}
\hline Characteristic & 1 & 2 & 3 & 4 & 5 \\
\hline Spatial scale & City or smaller & State/province & Country & World region & World \\
\hline
\end{tabular}

Table 5 Time horizon taxonomy criteria

\begin{tabular}{llllll}
\hline Characteristic & 1 & 2 & 3 & 4 & 5 \\
\hline Time horizon & $\begin{array}{c}\text { Immediate (less than 1 } \\
\text { year) }\end{array}$ & Short term (1-5 years) & $\begin{array}{c}\text { Medium term (5-10 } \\
\text { years) }\end{array}$ & Long term (10+ years) & $\begin{array}{c}\text { Ultra-long term (100+ } \\
\text { years) }\end{array}$ \\
\hline
\end{tabular}

framework. A coarse- or fine-grained systems dynamics model will always treat its object of analysis as a system of stocks and flows. For the modeler, it is important to ensure assumptions built into the modeling framework align with the represented scope. An aggregate production function model might not fit a rapidly evolving city well, as the framework abstracts away from many of the details that defines a "rapidly evolving city." On a practical level, an individual-based model of the world would create significant computing costs.

The choice of scale also impacts model interpretation and policy implications. What is the modeler trying to say with their model? A peak-oil model of a single oil well has a significantly different impact than a continent or world model. The scale dictates how "open" or "closed" a model can be. Spatial scale is a key component to the story behind an analysis_-it's the setting upon which characters act.

For the taxonomy, a category of 1 represents a city or smaller and a category of 5 represents models that have a global scope (Table 4).

\section{Time Horizon}

The time horizon characteristic evaluates the length of time a model represents. Some models, such as the Limits to Growth systems dynamics model, are intended to represent $200+$ years. Some models are designed to represent hours or days (e.g., electric utility day-ahead or weekly energy balancing models) but would be computationally expensive and/or incapable of running for a longer time horizon. The model framework or spatial scale does not inherently dictate model runtime: rather, the modeler choses a runtime based on their resources or extrinsic criteria.

Here, a category of 1 is reserved for models that evaluate immediately - that is, there is no time dimension. A category of 2 represents short term models, or less than a 5 year timeframe. An input-output model that uses 1 year's data would rank here. A category of 3 captures models that run in range of 5-10 years. Many models run long term scenarios, defined as more than 10 years. These include many integrated assessment models (IAMs) that model up to 2100.
Finally, ultra-long term models, such as those capturing the industrial revolution and continuing through 2100 , span time periods in excess of 100 years; these are categorized as a 5 (Table 5).

\section{Ethos}

The ethos characteristic describes how directly relatable the model is to reality, or to a specific application. ${ }^{4}$ Some models are intended to only explore concepts and theory, without direct links to an explicit dataset. These models do not provide prediction capabilities, but elucidate the consequences of theory (like the Limits to Growth model as discussed at the start of "The Biophysical Economic Modeling Landscape" section). Pure theory models are designed to understand and develop general theories without explicitly modeling a specific place or time period (Sherwood et al. 2017; Motesharrei et al. 2014; Epstein and Axtell 1996). At the other end of the spectrum are complete empirical and applied models that directly correlate to a specific location, time, and technology, but leave little room for making general observations. Ethos captures that characteristic spirit of the model's interpretation intentions. Many models fall between these two extremes - they are built with some links to a specific, real instance, but are based on theory or contain stylized elements. Often the specific and real data are used to validate theory (or at least the model), which may enable further model projection past the original dataset (i.e., hindcasting to prove model legitimacy).

Some researchers have suggested that, at least for certain modeling frameworks, few should fall in the middle of this characteristic. Sun et al. (2016) have suggested that modelers should stick to first principles or wholly rely on empirical research to limit the difficulty in model validation

\footnotetext{
${ }^{4}$ An abridged definition of ethos is "the characteristic spirit of a community as manifested in its aspirations." Here, we use ethos to mean "the characteristic spirit of a model as manifested by how the modeler interprets it." That is, researchers may have designed a model to be directly related to the real world, or merely to explore the implications of a theory.
} 
Table 6 Ethos taxonomy criteria

\begin{tabular}{llllll}
\hline Characteristic & 1 & 2 & 3 & 4 & 5 \\
\hline Ethos & $\begin{array}{c}\text { Pure theory, no connec- } \\
\text { tion to real world }\end{array}$ & $\begin{array}{c}\text { Mostly theory, limited } \\
\text { validation }\end{array}$ & $\begin{array}{c}\text { First principles validated } \\
\text { by real data (e.g., } \\
\text { IAMs) }\end{array}$ & $\begin{array}{c}\text { Mostly empirical, some } \\
\text { first principles }\end{array}$ & $\begin{array}{c}\text { Pure empirical (e.g., } \\
\text { econometric) }\end{array}$ \\
\hline
\end{tabular}

Table 7 Origins taxonomy criteria

\begin{tabular}{llllll}
\hline Characteristic & 1 & 2 & 3 & 4 & 5 \\
\hline Origins & Physical science model & Ecological or engineering costing & IAMs & Mainstream economics & $\begin{array}{c}\text { Behavioral economics/social } \\
\text { sciences }\end{array}$ \\
\hline
\end{tabular}

Table 8 Modeling mechanism taxonomy criteria

\begin{tabular}{llllll}
\hline Characteristic & 1 & 2 & 3 & 4 & 5 \\
\hline Mechanism & Simulation (model has to "run") & & Optimization & & Analysis (i.e., statistical modeling) \\
\hline
\end{tabular}

and acceptance. An applied model that contains stylized elements will be difficult to justify.

For the taxonomy, a category of 1 represents a purely theoretical model with no empirical input from the real world. A key example would be Sugarscape, an ABM that models the migration behavior of agents in a society that mines two generic resources.(Epstein and Axtell 1996) A category of 5 would be a purely empirical or econometric model, similar to many EROI studies (Heun et al. 2012). In the middle are IAMs - these are often developed from first principles and a combination of economic and engineering principles, but are calibrated and validated on real-world data (Table 6).

\section{Origins}

While somewhat different from other characteristics, origins is a categorical characteristic to evaluate how similar a given model is to traditional science and engineering techniques, or traditional economic or social models. As mentioned previously, many biophysical economic models have arisen from a combination of mainstream economics and science $\&$ engineering disciplines. These two broad disciplines often have their own language, assumptions, and nuanced understanding of complexities that may not be apparent to the other. Each field's perspectives influence their models. Therefore, the modeling framework origins influence the (apparent or hidden) assumptions and capabilities of current biophysical economic models.

For the taxonomy, a category of 1 indicates a pure science or engineering model without any economic influence. A category of 2 might be more of an engineering costing approach, techno-economic analysis, ecological model, or similar. A category of 3 represents a true blend of disciplines which often arises in integrated assessment models. A category of 4 represents mainstream economic models such as aggregate production functions. Finally, a category of 5 indicates models originating in behavioral economics or other social sciences_-often Agent-Based Models (Table 7).

\section{Mechanism}

Finally, the last characteristic stems from multiple interpretations of "model." Often, a scientific model is a simulation (either static, steady-state, or dynamic) that has to "run." This type of model is constructed with a set of equations and/or algorithms, often forming a computer program or script that must be executed to generate data. These simulation models are distinct from statistical models and optimization models. An optimization model is much stricter than a simulation, and attempts to find the best set of parameters for a given objective, subject to constraints. While also constructed with equations and/or algorithms, a statistical model is purely analysis of already-existing data, often to draw out relationships between variables (Sterman et al. 1991).

For the taxonomy, a category of 1 indicates a statistical model, a category of 3 indicates an optimization model, and a category of 5 indicates a simulation (Table 8$).^{5}$

\footnotetext{
5 Because there are only three categories for this characteristic, spaces two and four are unused in the taxonomy and analysis.
} 
Table 9 Taxonomy characterization applied to Brockway et al. (2017)

\begin{tabular}{lll}
\hline Characteristic & Category & Rationale \\
\hline Framework & 5 & Aggregate production function \\
Spatial scale & 3 & Country level analysis \\
Time horizon & 4 & 30 year timeframe \\
Ethos & 3 & First principles validated by data \\
Origins & 4 & Mainstream economics \\
Mechanism & 5 & Statistical analysis \\
\hline
\end{tabular}

Table 10 Taxonomy characterization applied to WORLD6 (Sverdrup et al. 2017a, b; Sverdrup and Olafsdottir 2018)

\begin{tabular}{lll}
\hline Characteristic & Category & Rationale \\
\hline Framework & 4 & Systems dynamics \\
Spatial scale & 5 & World \\
Time horizon & 5 & 500 year timeframe \\
Ethos & 2 & $\begin{array}{c}\text { Mostly theory, } \\
\text { informed by data }\end{array}$ \\
Origins & 2 & Systems science \\
Mechanism & 1 & Simulation \\
\hline
\end{tabular}

\section{Using the Taxonomy}

In this section, we classify four recently published biophysical economics models to demonstrate the use of this taxonomy. We chose one model for each level of the model framework characteristic (excluding individual-based modeling), to show how a specific combination of characteristics applies to a research topic. These combinations of characteristics are deliberate, and gaps between potential combinations and actualized combinations may point towards topics or research questions that may not have been modeled yet.

\section{Energy Rebound (Brockway et al. 2017)}

This article uses a modified aggregate production function to estimate national-level energy rebound for three countries (the US, UK, and China) over 30 years. This study extends a line of research that seeks to incorporate energy parameters into a standard macroeconomic model (Ayres and Warr 2010; Heun et al. 2017). In this paper, the objective is to determine how effective energy efficiency programs are at reducing energy use. The authors accomplish this by modifying a model that originated in macroeconomics, then econometrically fitting their equations to obtain their results. As such, this model can be categorized according to Table 9 .
Table 11 Taxonomy characterization applied to ACEGES (Voudouris et al. 2011)

\begin{tabular}{lll}
\hline Characteristic & Category & Rationale \\
\hline Framework & 2 & Agent-based model \\
Spatial scale & 5 & World \\
Time horizon & 4 & Long term, 10 + years \\
Ethos & 2 & Mostly theory, limited validation \\
Origins & 5 & Behavioral economics \\
Mechanism & 1 & Simulation \\
\hline
\end{tabular}

Table 12 Taxonomy characterization applied to Palmer (2017)

\begin{tabular}{lll}
\hline Characteristic & Category & Rationale \\
\hline Framework & 3 & Input-output model \\
Spatial scale & 3 & Country level analysis \\
Time horizon & 2 & 1 year timeframe \\
Ethos & 5 & Empirical \\
Origins & 4 & Mainstream economics \\
Mechanism & 5 & Analysis \\
\hline
\end{tabular}

\section{Mineral Extraction (Sverdrup et al. 2017a, b; Sverdrup and Olafsdottir 2018)}

Sverdrup et al. (2017a, b); Sverdrup and Olafsdottir (2018) are working to develop the WORLD6 systems dynamics model - a heavily extended and modified version of the same model used in Limits to Growth. These specific papers represent the development of a submodule that simulates global cobalt extraction and market dynamics. The model represents a global scale and simulates 500 years (1900-2400). The model was built using a combination of economic, geologic, and systems theory, and incorporates real-world data. As such, the model was categorized according to Table 10 .

\section{Oil Production (Voudouris et al. 2011)}

The ACEGES model was developed by Voudouris et al., who designed it for exploratory energy policy (Voudouris et al. 2011). They used the model to study oil production and peak oil. In this model, agents are countries (rather than individual oil companies or oil wells, which would make it an individual-based model). Each agent has a demand for oil, and may produce oil based on certain behavioral rules. In this way, the model avoids specific market-maximizing equations or an optimization of the supply-demand curve, which may better represent reality. The model is initialized with year 2001 data, allowing for 10 years of real-world data for validation (the paper was published in 2011). With that said, model calibration did not seem to be a central focus of the article, so the model 


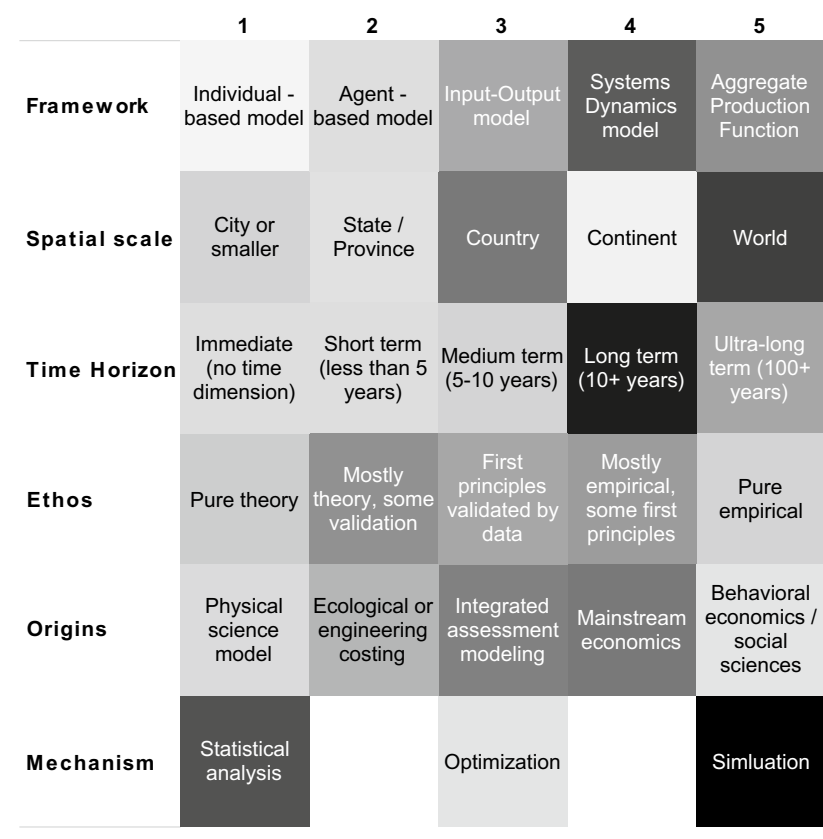

Fig. 6 Results of categorizing 110 BPE models across these 6 characteristics. Darker shaded areas of the taxonomy indicate more models fall within that category. Here, a black box represents 57 models

was categorized as a 2 on the modeling ethos characteristic. The model was run for 60 years, which was enough to simulate a peak oil and decline scenario. Because of this, the model was categorized according to Table 11. This model demonstrates the viability of using ABM to study biophysical economics. The nature of the modeling framework allowed for deep insight into indicators that are normally highly aggregated, such as production and consumption of oil for every country.

\section{EROI (Palmer 2017)}

Palmer combines Input-Output (IO) methodology with net-energy analysis to calculate the economy-wide energyreturn-on-investment (technically the gross external power ratio) of Australia for the 2013-2014 year. IO methodology originated in mainstream economics as a way to track economic output and linkages across industries. Palmer and many others have recently begun to utilize environmentallyextended input-output models to study biophysical economics indicators (King et al. 2015; King 2016; Brand-Correa et al. 2017; Heun et al. 2018). This paper was categorized as Table 12 .

\section{Summary of Example Categorization}

These examples represent a range of biophysical economic modeling frameworks, objectives, and mechanisms. The differences in modeling approach allow for different insights into the field. Each model was constructed to answer a specific hypothesis or research question-typically, that question, or the goal and scope of a research project, dictates many or all of a model's characteristics. So, a new question arises; are there currently research gaps within the field, indicated by unfilled combinations of these characteristics? If certain model characteristic patterns are unused, is it due to a legitimate research gap, or some inconsistency between the pattern's characteristics? We investigate this next.

\section{Qualitative Analysis of Modeling Space}

\section{Results by Characteristic}

Figure 6 shows the results of this analysis. The taxonomy shows each characteristic and its categories, and the shading of each box represents the number of models categorized within that category. This taxonomy indicates that most BPE models analyzed are either simulations or a statistical analysis with a time horizon longer than 10 years. Most models have a spatial scale at the country or world scale. There is a fairly even mix among modeling frameworks and modeling ethos, though individual-based models are rarely represented. Most models tend to have at least some validation and theory - there are few pure theory or pure empirical models within the dataset.

This taxonomy indicates that there may be gaps in the current modeling landscape-continent scale models are rare, as are medium term models. Few models arise from the behavioral economics or social science fields. And, there are few optimization models.

\section{Identifying Gaps}

To get a clearer picture of the BPE modeling landscape, we can plot the six characteristics within a correlation matrix to refine our understanding of research gaps. Figure 7 shows this correlation matrix. Here, each row (or column) represents a rating on a characteristic. Each box shows the number of models that were categorized according to that specific intersection of ratings. For example, the far left column shows how all individual-based models were categorized. The top-left box shows that there are two individual-based models in the dataset. Moving down the far left column, we note that these two models were both at the State/Province spatial scale and at the long term time horizon. We see that 


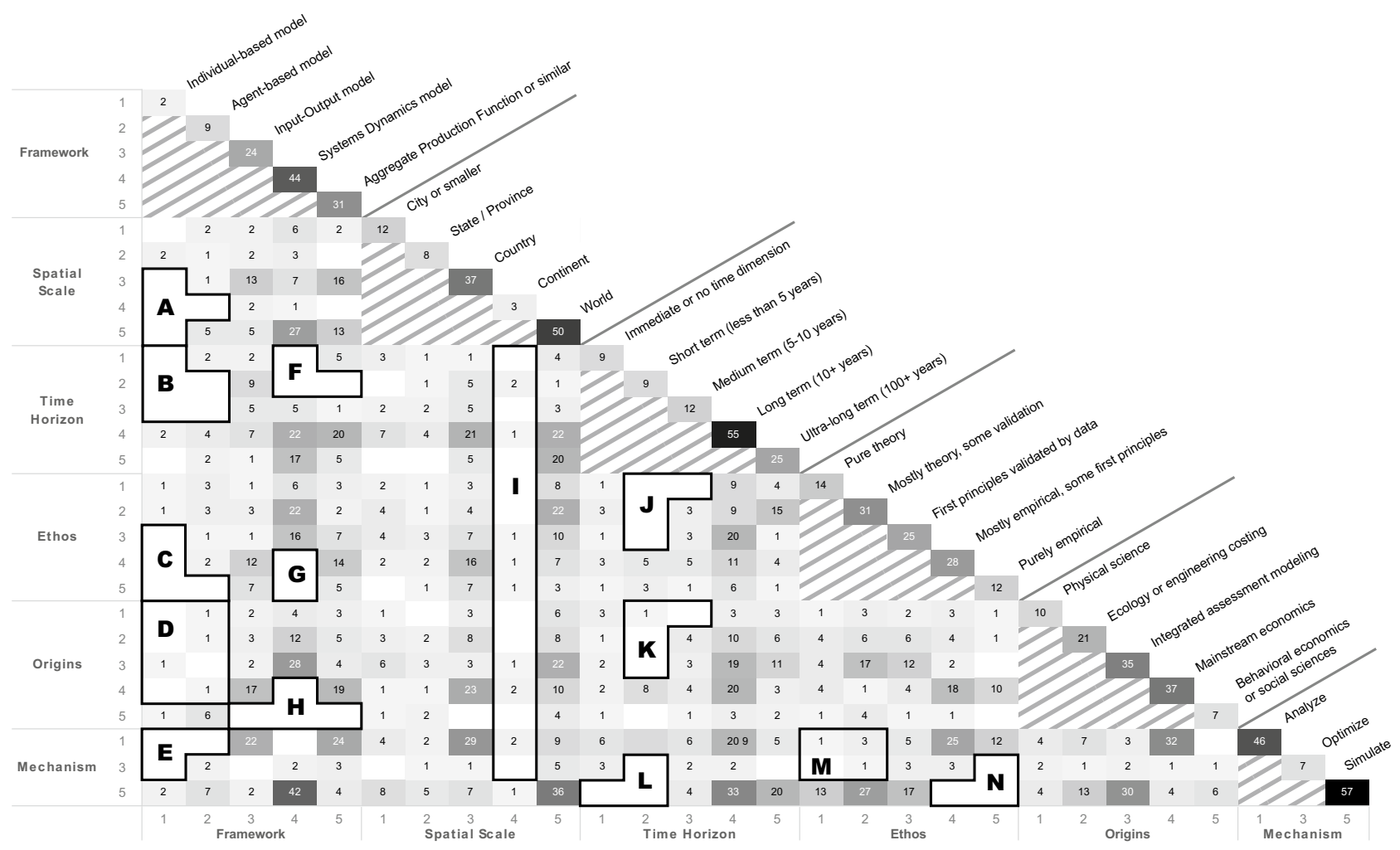

Fig. 7 Correlation matrix of 110 categorized BPE models across six characteristics. Darker cells indicate a greater number of models fall within that category. Gaps within the correlation matrix are outlined and labeled

one of these two individual-based models is at the "pure theory" ethos, while the other is "mostly theory, some validation." At the bottom of the far left column, we note that both individual-based models are simulations (there are no analysis or optimization individual-based models.)

The main diagonal of the matrix, where characteristics intersect with themselves, shows the same information as Fig. 6. The top left of the matrix shows that there are two individual-based models and eight agent-based models, for example. These diagonal boxes show the total number of models categorized in a single characteristic. Looking at the bottom right of the matrix, there are 57 simulation models. These 57 simulation models are distributed across each of the other characteristics-reading the last row of this matrix, we see that of the 57 simulations, 42 are systems dynamics models. 36 of the 57 are at the world spatial scale. 33 of the 57 have a long term time horizon, and so on.

The correlation matrix indicates several gaps within the modeling landscape. These gaps are areas of the matrix in which few, if any, models were categorized. Each gap has been highlighted on Fig. 7 and labeled with a letter. We break down these modeling gaps and provide commentary based on the columns of Fig. 7, from left to right. For each gap, we conclude whether or not future research might be able to fill it and provide a potential research question if possible. Some gaps may be "open" but unfillable due to inherent modeling limitations or conflict within the characteristics (such as a systems dynamics statistical analysis).

\section{Agent-Based Modeling Gaps}

Box A shows that there are no individual-based models at the country, continent, or world scale. This is likely a computational limitation-instantiating enough individuals to fill a world model would be prohibitively expensive. In contrast, agent-based models might be able to model the world if agents are appropriately defined, such as "country" agents. Or, if only a small segment of the world is modeled, such as an agent-based model of the world's oil extraction (Voudouris et al. 2011). Gap is possible to be filled, if agents 
are appropriately defined. How might local or "global" policies help competing countries within Africa overcome future energy shortages while maintaining or improving quality-of-life?

Box B indicates that individual-based and agent-based models tend to extend across a long term time horizon. Few agent-based models occur in short- or medium term timeframes. Gap is possible to be filled. What short term social dynamics, including international trade agreement or supplier contract structure, limit resiliency in the face of sudden physical supply shocks?

Box $\mathbf{C}$ indicates that individual-based and agent-based models are usually theoretical. Due to the nature of agentbased modeling, it might be impossible to build a purely empirical model. Agent-based models require significant modeling assumptions (ideally based on theory) that extend beyond a pure data-based analysis. Gap is unlikely to be filled.

Box D indicates that agent-based models are grounded in behavioral economics or social science. This is because agent-based models originated in the social sciences, and the framework is significantly dependent on social dynamics and interactions. Gap is unlikely to be filled.

Box $\mathbf{E}$ shows that an agent-based model by definition is a simulation. It cannot be a statistical analysis. An agent-based model could potentially be constrained by an optimization framework but these are rare. Gap is unlikely to be filled.

\section{Systems Dynamics Gaps}

Box $\mathbf{F}$ shows that there are no short term systems dynamics models. So far, system dynamics models have been used to study long term and ultra-long term time horizons. It may be easier to use an input-output model or other model structure to study short term time horizons. Gap is possible to be filled, if the systems dynamics model is built appropriately. Is there enough rare-earth element mining capacity for the European Union to dramatically ramp-up energy storage technologies in the short term ( $<5$ years)? How might prices and supply react?

Boxes $\mathbf{G}$ and $\mathbf{H}$ indicate that systems dynamics models are not purely empirical, and are a mix of engineering, systems thinking, and economics. Similar to agent-based models, this gap appears to be a byproduct of the systems dynamics framework. Gap is unlikely to be filled.

\section{Continent Spatial Scale Gap}

Box I shows that across all other modeling characteristics, continent scale models are rare. It is interesting to note that most simulation models work at the world scale, while most statistical analysis models work at the country scale. An apparent gap exists in scaling these modeling mechanisms to alternate spatial scales. This might be attributed to low data availability at the continent scale; country or worldwide data may be easier to obtain. There seems to be much room for models of a specific continent, particularly if there is an emphasis on ocean- vs land-based trade or supply routes. Gap is possible to be filled. Does one continent have an inherent advantage over others for an energy resource transition due to distribution of resources? How has geographic distance between suppliers and manufacturers affected EROI and costs for various energy technologies?

\section{Time Horizon Gap}

The majority of time horizon gaps occur for the short term (less than 5 years) time horizon models. Boxes $\mathbf{J}, \mathbf{K}$, and $\mathbf{L}$ show that only Input-Output models currently model the short term. As input-output models usually work with a single year of economic data, this makes sense. However, the gap indicates that short term simulations $(\mathbf{B o x} \mathbf{L})$ do not exist. This may be because economies are not facing fundamental physical constraints in the short term, and so a short term biophysical model might reduce down to a standard economic model. However, there is potential for sudden supply shocks within the short term. This might require a biophysical model to understand. We believe this is certainly a research gap that ought to be further studied. Gap is possible to be filled. What short term economic and environmental effects would occur due to a repeat of the 1973 oil crisis in today's economy?

\section{Ethos Gap}

Box $\mathbf{M}$ indicates that few statistical analysis or optimization models are purely theoretical. Conversely, Box $\mathbf{N}$ indicates that few simulations are purely empirical. This makes sense-a certain level of abstraction is necessary to create a tractable simulation. That is, simulations rely on theory. In parallel, analytic models rely on empirical data. Analytic models may incorporate theoretical underpinnings (such as the concept of EROI), but they tend to be far more empirical than theory. As such, these research gaps make sense and seem to be a product of the modeling mechanism, rather than an underdeveloped area of the landscape. Gap is unlikely to be filled.

\section{Other Observations}

Few optimization models were found in the literature. This might be a consequence of the requirements for optimization-biophysical economics tends to be complicated and complex in a way ill-suited for an optimization routine. 
Optimization requires a well-specified objective and wellspecified constraints. Within the context of economics, an optimization model might also require economic actors to maximize their utility and perfectly value everything-a contentious assumption.

\section{Conclusion and Future Research}

Biophysical models of the economy are necessarily multidisciplinary because they model both human and natural systems, as well as the relationships between them. Because of the multi-disciplinary nature, biophysical economics modeling approaches are published across a large spectrum of academic journals. The primary contribution of this study has been to develop a taxonomy of biophysical economics models as a way to understand the current landscape of this diverse body of work. Using the taxonomy to classify the last 10 years of published studies reveals which approaches have been used more than others. The more densely populated cells of the taxonomy include systems dynamics models, global models, long time horizon, and those originating from either integrated assessment modeling or mainstream economics. Several gaps in the taxonomy suggest that some modeling approaches have yet to be explored in the published literature. Some of the gaps are expected, and are not likely to be productive areas to explore. For example, the Ethos gaps are a natural result of the context of how models are developed. On the other hand, the lack of agent-based models, and models at the city, state, or continental scale are likely to be promising avenues for the future. That these gaps exist indicates that certain research questions have yet to be addressed. We believe there is merit to building models in these gaps. By expanding the application of these biophysical modeling approaches we can deepen the understanding of how the economy can work within its biophysical constraints.

Funding This material is based upon work supported by the National Science Foundation Graduate Research Fellowship under Grant No. 1744593.

\section{Compliance with Ethical Standards}

Conflict of interest On behalf of all authors, the corresponding author states that there is no conflict of interest.
Open Access This article is licensed under a Creative Commons Attribution 4.0 International License, which permits use, sharing, adaptation, distribution and reproduction in any medium or format, as long as you give appropriate credit to the original author(s) and the source, provide a link to the Creative Commons licence, and indicate if changes were made. The images or other third party material in this article are included in the article's Creative Commons licence, unless indicated otherwise in a credit line to the material. If material is not included in the article's Creative Commons licence and your intended use is not permitted by statutory regulation or exceeds the permitted use, you will need to obtain permission directly from the copyright holder. To view a copy of this licence, visit http://creativecommons.org/licenses/by/4.0/.

\section{Appendices}

\section{Appendix A BPE Model Publishing Across Journals}

Figure 8 shows the number of results from our initial literature search described in the "Article Selection Criteria" section. The colors represent whether or not an article made it through the entire screening process; the black bars represent the BPE models categorized and included in the results

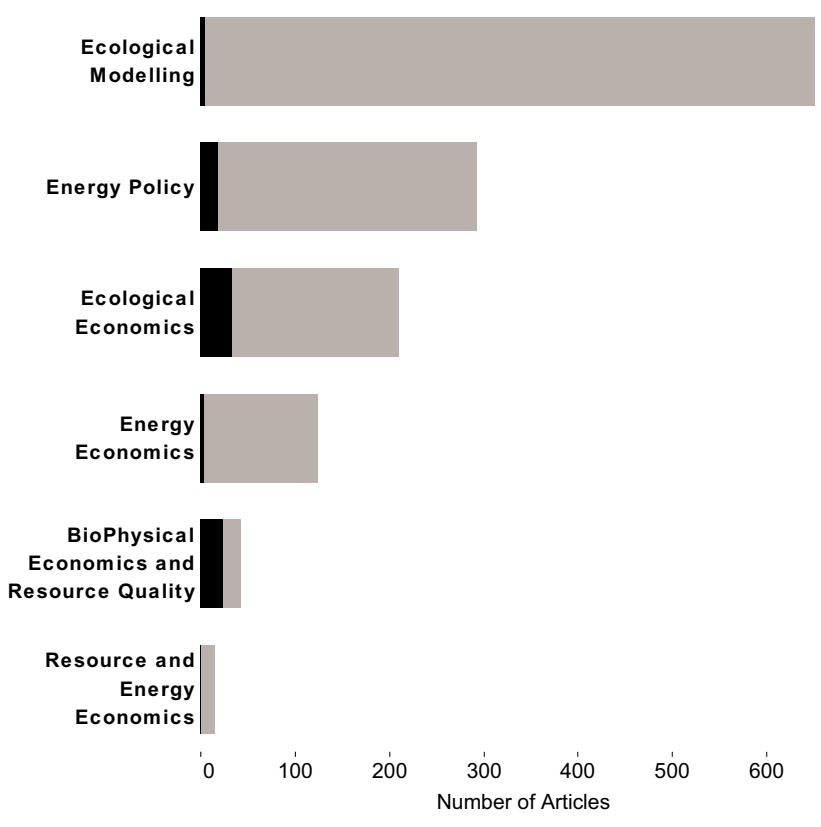

Fig. 8 Number of articles from initial literature search for each journal. The gray color represents articles that were excluded from categorization. The black color represents articles that made it through the screening process and were categorized 
of this paper. The gray bars represent all other papers that were screened out of our analysis.

The majority of articles were from the journal Ecological Modelling, possibly because the name of the journal included the "model" keyword, one of our search parameters. Ecological Modelling also had the lowest percentage of BPE models within the journal, suggesting that BPE does not align well with the goal and scope of the journal (the same might be said of Resource and Energy Economics, which is surprising to the authors).

The largest number of BPE models was found in the journal Ecological Economics. This suggests a certain amount of overlap between Ecological Economics and BPE. The journal Biophysical Economics and Resource Quality (BERQ, now Biophysical Economics and Sustainability) has the largest percentage of BPE models, followed by Ecological
Economics and Energy Policy. BERQ's high percentage indicates that its scope fully aligns with BPE and the editors filter models appropriately. Although BERQ was launched in 2016, the rate of non-BERQ BPE models has remained fairly steady during the time period under review (2009-2019). This indicates that field has grown over the past 3 years, and BERQ has captured this growth without negatively affecting publishing rates in other journals.

\section{Appendix B Full Taxonomy Scheme}

For reference, the full taxonomy scheme is supplied in Table 13.

Table 13 Full model taxonomy scheme

\begin{tabular}{|c|c|c|c|c|c|}
\hline \multirow[t]{2}{*}{ Characteristic } & \multicolumn{5}{|l|}{ Category } \\
\hline & 1 & 2 & 3 & 4 & 5 \\
\hline Framework & Individual-based model & Agent-based model & Input-output model & Systems dynamics & $\begin{array}{l}\text { Aggregate production } \\
\text { function }\end{array}$ \\
\hline Spatial scale & City or smaller & State/province & Country & Continent/world region & World \\
\hline Time horizon & $\begin{array}{l}\text { Immediate (less than } 1 \\
\text { year) }\end{array}$ & Short term (1-5 years) & $\begin{array}{l}\text { Medium term }(5-10 \\
\text { years) }\end{array}$ & Long term $(10+$ years $)$ & $\begin{array}{l}\text { Ultra-long term }(100+ \\
\text { years) }\end{array}$ \\
\hline Ethos & $\begin{array}{l}\text { Pure theory, no connec- } \\
\text { tion to real world }\end{array}$ & $\begin{array}{l}\text { Mostly theory, limited } \\
\text { validation }\end{array}$ & $\begin{array}{l}\text { First principles } \\
\text { validated by real data } \\
\text { (e.g., IAMs) }\end{array}$ & $\begin{array}{l}\text { Mostly empirical, some } \\
\text { first principles }\end{array}$ & $\begin{array}{l}\text { Pure empirical (e.g., } \\
\text { econometric) }\end{array}$ \\
\hline Origins & Physical science model & $\begin{array}{l}\text { Ecological or engineer- } \\
\text { ing costing }\end{array}$ & IAMs & Mainstream economics & $\begin{array}{l}\text { Behavioral economics/ } \\
\text { social sciences }\end{array}$ \\
\hline Mechanism & $\begin{array}{l}\text { Simulation (model has } \\
\text { to "run") }\end{array}$ & & Optimization & & $\begin{array}{l}\text { Analysis (i.e., statistical } \\
\text { modeling) }\end{array}$ \\
\hline
\end{tabular}




\section{References}

Abram JJ, Dyke JG (2018) Structural loop analysis of complex ecological systems. Ecol Econ 154:333-342. https://doi.org/10.1016/J. ECOLECON.2018.08.011

Ayres RU (1999) The second law, the fourth law, recycling and limits to growth. Ecol Econ 29(3):473-483. https://doi.org/10.1016/S0921 $-8009(98) 00098-6$

Ayres RU, Warr B (2010) The economic growth engine: how energy and work drive material prosperity. Edward Elgar Publishing, Cheltenham

Bardi U (2011) The limits to growth revisited. Springer, New York

Brand-Correa LI, Brockway PE, Copeland CL, Foxon TJ, Owen A, Taylor PG, Brand-Correa LI, Brockway PE, Copeland CL, Foxon TJ, Owen A, Taylor PG (2017) Developing an input-output based method to estimate a national-level energy return on investment (EROI). Energies 10(4):534. https://doi.org/10.3390/en10040534 , http://www.mdpi.com/1996-1073/10/4/534

Brandt AR, Dale M, Brandt AR, Dale M (2011) A general mathematical framework for calculating systems-scale efficiency of energy extraction and conversion: energy return on investment (EROI) and other energy return ratios. Energies 4(8):12111245. https://doi.org/10.3390/en4081211. http://www.mdpi. com/1996-1073/4/8/1211

Brockway P, Saunders H, Heun M, Foxon T, Steinberger J, Barrett J, Sorrell S (2017) Energy rebound as a potential threat to a lowcarbon future: findings from a new exergy-based national-level rebound approach. Energies 10(1):51. https://doi.org/10.3390/ en10010051. http://www.mdpi.com/1996-1073/10/1/51

Butnar I, Llop M (2011) Structural decomposition analysis and inputoutput subsystems: changes in $\mathrm{CO}_{2}$ emissions of Spanish service sectors (2000-2005). Ecol Econ 70(11):2012-2019. https://doi. org/10.1016/j.ecolecon.2011.05.017. https://linkinghub.elsevier. com/retrieve/pii/S0921800911002060

Clark CW (2010) Mathematical bioeconomics: the mathematics of conservation. Wiley, Hoboken

Cleveland CJ, Costanza R, Hall CAS, Kaufmann R (1984) Energy and the U.S. economy: a biophysical perspective. Science 225(4665):890-897

Cleveland CJ (1987) Biophysical economics: historical perspective and current research trends. Ecol Model 38:47. http://faculty.washi ngton.edu/gmobus/Energy/Cleveland_1987_HistoryEconomic s.pdf

Cleveland CJ (1999) Biophysical Economics: From Physiocracy to Ecological Economics and Industrial Ecology. In: Mayumi K, Gowdy JM (eds) Bioeconomics and sustainability: essays in honor of Nicholas Georgescu-Roegen, Edward Elgar, Northhampton, chap 8, pp 125-154

Cottrell F (1955) Energy and society the relation between energy, social changes, and economic development. McGraw-Hill, New York

Dale M, Krumdieck S, Bodger P (2011) Net energy yield from production of conventional oil. Energy Policy 39(11):7095-7102. https ://doi.org/10.1016/j.enpol.2011.08.021

Dale M, Krumdieck S, Bodger P (2012a) Global energy modelling-a biophysical approach (GEMBA) part 1: an overview of biophysical economics. Ecol Econ 73:152-157. https://doi. org/10.1016/j.ecolecon.2011.10.014

Dale M, Krumdieck S, Bodger P (2012b) Global energy modelling-a biophysical approach (GEMBA) Part 2: methodology. Ecol Econ 73:158-167. https://doi.org/10.1016/j.ecole con.2011.10.028

Daly HE (1991) Steady-state economics. Island Press. https ://books.google.com/books?hl=en \&lr=\&id=DwC 8 B wAAQB AJ \&o $=$ fnd $\& p g=$ PR $2 \& d q=$ Steady-State + Econo
mics\&ots=4RIrX1hh-6\&sig $=$ ZWMdXMpHmw4IkyB zf4 Vd $\mathrm{vscW} 6 \mathrm{qk} \# \mathrm{v}=$ onepage $\& \mathrm{q}=$ Steady-StateEconomics $\& \mathrm{f}=$ false

Daly HE (2005) Economics in a full world. Sci Am 293(3):100-107. https://doi.org/10.1038/scientificamerican0905-100

Earles JM, Halog A (2011) Consequential life cycle assessment: a review. Int J Life Cycle Assess 16(5):445-453. https://doi. org/10.1007/s11367-011-0275-9

Epstein JM, Axtell R (1996) Growing artificial societies: social science from the bottom up. The Brookings Institution, Washington, D.C., https://books.google.com/books?hl=en\&lr=\&id=xXvel Ss 2 caQC \&oi $=$ fnd \&pg $=$ PA $1 \& d q=$ growing + artificial + socie ties\&ots=_hL_5zPGsu\&sig=QtMAlHJBYtSIZCaxyO04IeRdk $\mathrm{DE} \# \mathrm{v}=$ onepage $\& \mathrm{q}=$ growingartificialsocieties $\& \mathrm{f}=\mathrm{false}$

Foudi S (2012) The role of farmers' property rights in soil ecosystem services conservation. Ecol Econ 83:90-96. https://doi. org/10.1016/j.ecolecon.2012.08.015, https://linkinghub.elsevier. $\mathrm{com} /$ retrieve/pii/S092180091200331X

Georgescu-Roegen N (1971) The entropy law and the economic process. Harvard University Press, Cambridge. http://www.hup.harva rd.edu/catalog.php?isbn $=9780674281653$

Ghisellini P, Cialani C, Ulgiati S (2016) A review on circular economy: the expected transition to a balanced interplay of environmental and economic systems. J. Clean. Prod. 114:11-32. https://doi. org/10.1016/J.JCLEPRO.2015.09.007

Hall CAS, Klitgaard KA (2018) Energy and the wealth of nations. Springer, New York

Hall CAS, Cleveland CJ, Kaufman R (1986) Energy and resource quality: the ecology of the economic process, 1 st edn. WileyInterscience, New York

Hamill L, Gilbert N (2015) Agent-based modelling in economics. Wiley, Chichester. https://doi.org/10.1002/9781118945520

Han D, Chen Y, Zhang C, Ren Y, Xue Y, Wan R (2017) Evaluating impacts of intensive shellfish aquaculture on a semi-closed marine ecosystem. Ecol Model 359:193-200. https://doi.org/10.1016/j. ecolmodel.2017.05.024, https://linkinghub.elsevier.com/retrieve/ pii/S0304380017301849

Hansen P, Liu X, Morrison GM (2019) Agent-based modelling and socio-technical energy transitions: a systematic literature review. Energy Res Soc Sci 49:41-52. https://doi.org/10.1016/J. ERSS.2018.10.021

Hardt L, Barrett J, Brockway P, Foxon TJ, Heun MK, Owen A, Taylor PG (2017) Outsourcing or efficiency? Investigating the decline in final energy consumption in the UK productive sectors. Energy Procedia 142:2409-2414. https://doi.org/10.1016/j. egypro.2017.12.175. https://linkinghub.elsevier.com/retrieve/pii/ S1876610217359039

Heun MK, de Wit M (2012) Energy return on (energy) invested (EROI), oil prices, and energy transitions. Energy Policy 40(1):147-158. https://doi.org/10.1016/j.enpol.2011.09.008. https://linkinghub .elsevier.com/retrieve/pii/S0301421511006975

Heun MK, Carbajales-Dale M, Haney BR (2015) Beyond GDP, lectures notes in energy. Springer, Cham. https://doi.org/10.1007/978-3319-12820-7

Heun MK, Santos J, Brockway PE, Pruim R, Domingos T, Sakai M, Heun MK, Santos J, Brockway PE, Pruim R, Domingos T, Sakai M (2017) From theory to econometrics to energy policy: cautionary tales for policymaking using aggregate production functions. Energies 10(2):203. https://doi.org/10.3390/en10020203. http:// www.mdpi.com/1996-1073/10/2/203

Heun MK, Owen A, Brockway PE (2018) A physical supply-use table framework for energy analysis on the energy conversion chain. Appl Energy 226:1134-1162

Hintermann B (2012) Pricing emission permits in the absence of abatement. Energy Econ 34(5):1329-1340. https://doi.org/10.1016/j. 
eneco.2012.06.005. https://linkinghub.elsevier.com/retrieve/pii/ S0140988312001119

Hubbert M (1949) Energy from fossil fuels. Science 109-2823(February):103-109. https://www.jstor.org/stable/16766 18 ?seq=1\#metadata_info_tab_contents

Jevons W (1866) The coal question: an enquiry concerning the progress of the nation, and the probable exhaustion of our coal-mines. Making of the modern world, part 2. Macmillan, New York

Jin W, Xu L, Yang Z (2009) Modeling a policy making framework for urban sustainability: incorporating system dynamics into the ecological footprint. Ecol Econ 68(12):2938-2949. https://doi. org/10.1016/j.ecolecon.2009.06.010

Kåberger T, Månsson B (2001) Entropy and economic processesphysics perspectives. Ecol Econ 36(1):165-179. https://doi. org/10.1016/S0921-8009(00)00225-1

Kelly MA, Bruestle S (2011) Trend of subjects published in economics journals 1969-2007. Econ Inquiry 49(3):658-673. https://doi.org /10.1111/j.1465-7295.2010.00282.x

King C, Maxwell J, Donovan A, King CW, Maxwell JP, Donovan A (2015) Comparing world economic and net energy metrics, part 2: total economy expenditure perspective. Energies 8(11):12,97512,996, https://doi.org/10.3390/en81112347. http://www.mdpi. com/1996-1073/8/11/12347

King CW (2016) Information theory to assess relations between energy and structure of the US economy over time. BioPhys Econ Res Qual 1(2):10. https://doi.org/10.1007/s41247-016-0011-y

Li FGN, Trutnevyte E, Strachan N (2015) A review of socio-technical energy transition (STET) models. Technol Forecast Soc Change 100:290-305. https://doi.org/10.1016/J.TECHFORE.2015.07.017

Lotka AJ (1922) Contribution to the energetics of evolution. Proc Natl Acad Sci USA 8(6):147-151. https://doi.org/10.1073/ PNAS.8.6.147

Malthus TR (1878) An essay on the principle of population: or, a view of its past and present effects on human happiness, with an inquiry into our prospects respecting the future removal or mitigation of the evils which it occasions. Reeves and Turner, London

Meadows D, Randers J (2012) The limits to growth: the 30-year update. Routledge, Abingdon

Meadows DH, Meadows DL, Randers J, Behrens WW (1972) The limits to growth. Club of Rome, New York

Meadows DH, Randers J, Meadows DL (2004) Limits to growth: the 30-year update, 3rd edn. Chelsea Green Publishing, White River Junction, Vt. https://www.amazon.com/Limits-Growth-DonellaH-Meadows/dp/193149858X/ref=sr_1_1?ie=UTF8\&qid=14689 $50955 \& \mathrm{sr}=8-1 \&$ keywords $=$ limits + to + growth

Melgar-Melgar RE, Hall CAS (2020) Why ecological economics needs to return to its roots: the biophysical foundation of socio-economic systems. Ecol Econ 169:106567

Miller RE, Blair PD (2009) Historical Notes on the Development of Leontief's Input-Output Analysis. In: Input-Output Analysis, Cambridge University Press, Cambridge, pp 724-737, https:// doi.org/10.1017/CBO9780511626982.018. https://www.cambr idge.org/core/product/identifier/CBO9780511626982A184/type/ book_part

Motesharrei S, Rivas J, Kalnay E (2014) Human and nature dynamics (HANDY): modeling inequality and use of resources in the collapse or sustainability of societies. Ecol Econ 101:90-102. https ://doi.org/10.1016/J.ECOLECON.2014.02.014

Murphy DJ, Hall CAS (2010) Year in review; EROI or energy return on (energy) invested. Annals of the New York Academy of Sciences. Ecol Econ Rev 1185:102-118, https://doi.org/10.111 1/j.1749-6632.2009.05282.x

North MJMJ, Macal CM (2007) Managing business complexity: discovering strategic solutions with agent-based modeling and simulation. Oxford University Press, Oxford
Odum HT (1994) Ecological and general systems: an introduction to systems ecology (2nd ed.) University Press of Colorado, Niwot, Colorado. University Press of Colorado. http://cds.cern.ch/recor $\mathrm{d} / 1460154$

Palmer G (2017) An input-output based net-energy assessment of an electricity supply industry. Energy 141:1504-1516. https://doi. org/10.1016/J.ENERGY.2017.11.072

Palmer G (2018) A biophysical perspective of IPCC integrated energy modelling. Energies 11(4):839. https://doi.org/10.3390/en110 40839

Quesnay F, Kuczynski M, Meek RL (1972) Quesnay's Tableau economique. Macmillan, New York

Rai V, Robinson SA (2015) Agent-based modeling of energy technology adoption: empirical integration of social, behavioral, economic, and environmental factors. Environ Model Softw 70:163177. https://doi.org/10.1016/j.envsoft.2015.04.014

Rashleigh B, Barber MC, Walters DM (2009) Foodweb modeling for polychlorinated biphenyls (PCBs) in the Twelvemile Creek Arm of Lake Hartwell, South Carolina, USA. Ecol Model 220(2):254264. https://doi.org/10.1016/j.ecolmodel.2008.09.007

Røpke I (2004) The early history of modern ecological economics. Ecol Econ 50(3-4):293-314

Rye CD, Jackson T (2018) A review of EROEI-dynamics energytransition models. Energy Policy 122:260-272. https://doi. org/10.1016/j.enpol.2018.06.041

Sherwood J, Ditta A, Haney B, Haarsma L, Carbajales-Dale M (2017) Resource criticality in modern economies: agent-based model demonstrates vulnerabilities from technological interdependence. BioPhys Econ Res Qual 2(3):9. https://doi.org/10.1007/ s41247-017-0026-Z

Sterman JD (1991) A skeptic's guide to computer models. Manag Nation Microcomput Softw Cat 2:209-229

Sun Z, Lorscheid I, Millington JD, Lauf S, Magliocca NR, Groeneveld J, Balbi S, Nolzen H, Müller B, Schulze J, Buchmann CM (2016) Simple or complicated agent-based models? A complicated issue. Environ Model Softw 86:56-67. https://doi.org/10.1016/J.ENVSO FT.2016.09.006

Sverdrup HU, Olafsdottir AH (2018) A system dynamics model assessment of the supply of niobium and tantalum using the WORLD6 model. BioPhys Econ Res Qual 3(2):5. https://doi.org/10.1007/ s41247-018-0038-3

Sverdrup HU, Koca D, Schlyter P (2017a) A simple system dynamics model for the global production rate of sand, gravel, crushed rock and stone, market prices and long-term supply embedded into the WORLD6 model. BioPhys Econ Res Qual 2(2):8. https://doi. org/10.1007/s41247-017-0023-2

Sverdrup HU, Olafsdottir AH, Ragnarsdottir KV (2017b) Modelling global wolfram mining, secondary extraction, supply, stocks-insociety, recycling, market price and resources, using the world6 system dynamics model. BioPhys Econ Res Qual 2(3):11. https ://doi.org/10.1007/s41247-017-0028-x

Voudouris V, Stasinopoulos D, Rigby R, Di Maio C (2011) The ACEGES laboratory for energy policy: exploring the production of crude oil. Energy Policy 39(9):5480-5489. https://doi. org/10.1016/j.enpol.2011.05.014

Publisher's Note Springer Nature remains neutral with regard to jurisdictional claims in published maps and institutional affiliations. 